(c) 2003 Springer-Verlag. Reprinted with permission from Carbonell, N. and Stephanidis, C. (editors),

Universal Access: Theoretical Perspectives, Practice, and Experience. 7th ERCIM International Workshop on User Interfaces for All. Paris, France, 24-25 October 2002. Revised Papers, Lecture Notes in Computer Science 2615. Heidelberg, Germany, Springer-Verlag, pages 179-186.

\title{
Digital Television for All: User Preferences and Designers' Views on What Would Suit the User
}

\author{
Leena Eronen \\ Telecommunications Software and Multimedia Laboratory, \\ Helsinki University of Technology, P.O.Box 5400, \\ FI-02015 HUT, Finland \\ leronen@niksula.hut.fi
}

\begin{abstract}
This paper presents results from a user study and a set of design sessions conducted in a broadcasting company. During the design sessions, the designers created new concepts of interactive television programs for given TV viewers. The creative work was based on user profiles collected in the preceding user study. The aim of research was to include the future users into the product development in the early stages of new product design. Both TV viewers and designers created innovations of future interactive applications and the results are discussed.
\end{abstract}

\section{Introduction}

Design activities have been called as 'a process of communication among various audiences' [3]. Interactive television programs and services for digital television are an example of novel products that must meet the needs of a broad range of audiences. For example, re-design of many consumer products is based on modifications made to the latest product versions to meet the new user needs. Sometimes a fresh marketing campaign will do. Concept design of new and novel products on the other hand faces many challenges. Modifications made to previous product versions are not enough for the television audience, as TV viewers want to get surprised by new television programs, not the old ones.

Interactive television programs and applications have been a subject of research in a number of studies. There are results from prototyping personalized TV news [9], usability testing Electronic Program Guide prototypes [6] and designing on-screen displays and remote controls [8]. There are also results from an ethnographic study of set-top-box use [10], a study resulting in a set of user groups for digital television [4] and a user study resulting in new concepts of interactive television programs made by TV viewers [5]. The next subsection deals with issues concerning user research and user centered concept design for digital television. 


\subsection{Methods}

The study presented here consists of a user study and a set of design sessions held in a broadcasting company. It is a continuation of a study resulting in a set of user groups for digital television [4]. The aim of research was to include the future users into the product development in the early stages of new product design. The new products are interactive television programs and applications for digital television. The user study took place in study participants' home environment. Five women and five men in the age range of 16-78 years received an envelope with questionnaires, separate questions, two diaries and a disposable camera. The approach has been adapted from a research called 'Cultural Probes' and other, more traditional ethnographic methods [7, 1, 10]. The study participants also designed innovations of future interactive applications for themselves. A subsequent one-hour interview with the researcher revealed more of the study participants' needs for specific types of information and their thoughts of the television in the future. The interview materials were analyzed to find important examples and user experiences [11]. The approach was not an ethnographic user study as it was the user study participants who collected the data instead of researchers. The approach enabled the study participants themselves to gather the results in their home environment, explain them and give their interpretations as why events happened. An ethnographic study made by an observer would not reveal enough of the user's motives to watch television.

A series of five design sessions followed in the public service broadcasting company YLE (Finnish Broadcasting Company). YLE's share of total TV viewing in the Finnish-language television network was $43 \%$ during year 2001. Each session included a researcher and two participants from YLE: concept designers, producers, television editors and audience researchers. Altogether ten participants from YLE took part in the sessions which took 60-90 minutes each. The session participants explored the user profile, discussed about their findings and then designed new concepts of interactive television programs. A lively discussion provoked the session participants to imitate the program hosts, television announcers and the studio audience. The new program concepts were therefore created with the help of storytelling and role playing $[3,2]$. The aim of each session was to concentrate specifically on one TV viewer at a time instead of groups of people familiar from the audience research. At the end of a session, the user's innovations were presented to session participants as a feedback. They could now compare their new concepts to user's innovations. This was a way to provide an instant feedback to designers.

\section{Results}

Results from the user study and the five design sessions are presented here next. In the user study the emphasis was put on finding user preferences and expectations instead of particular user needs. Digital television is a novel product and it is not possible to perform research on user needs concerning a product or service the user has never used before. For new concepts of interactive television programs and services, it was 


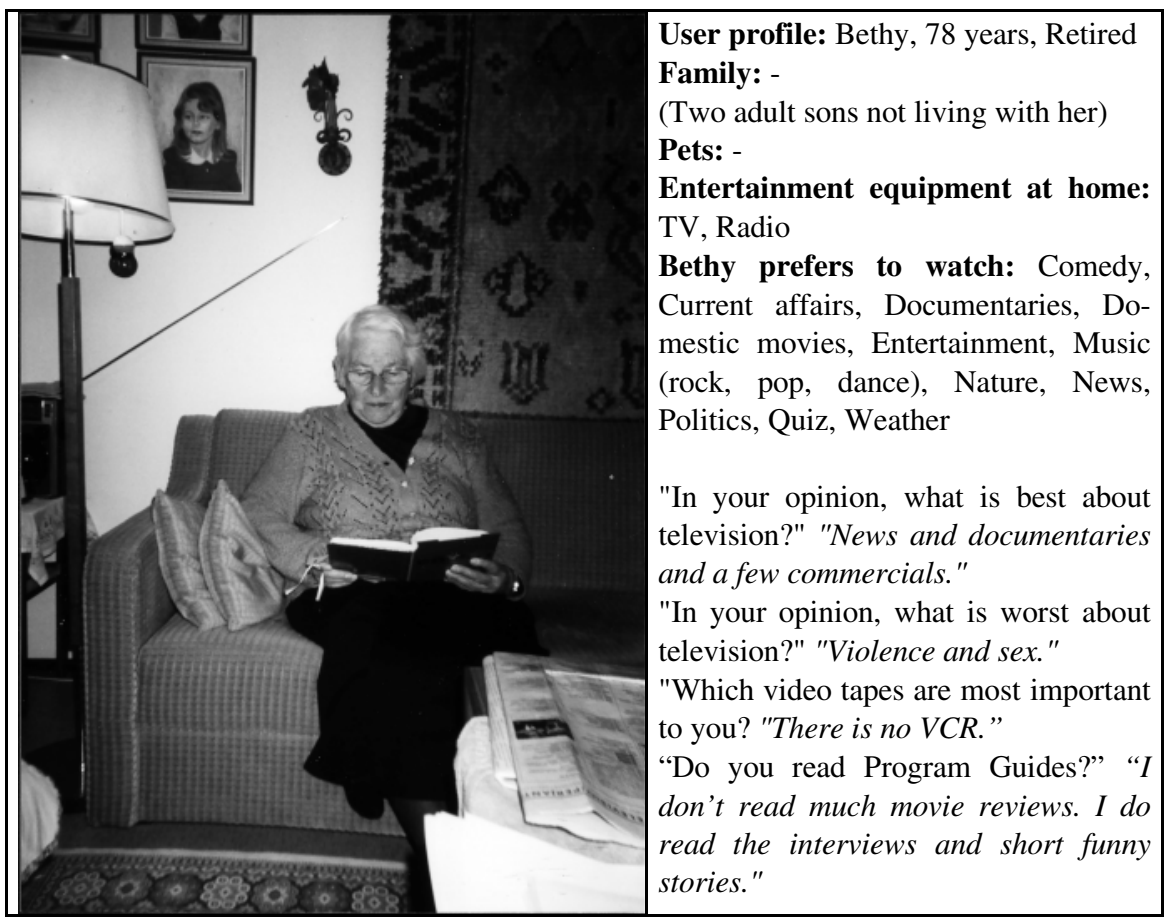

Fig. 1. Bethy on her leisure time

anticipated that the user interaction can take place in four different ways. There is the interaction with the remote control and the set-top-box, an SMS sent from a mobile phone, a phone call or a postcard sent to the TV show.

\subsection{User Study}

User study results are responses to questionnaires, diaries, photographs, users' innovations and notes from the interviews [5]. The study participants also made scenarios about what their television will look like in year 2006, five years ahead of the present moment. The study results were collected in user profiles. Each profile is 8-18 pages long. One of the user profiles is presented here next. For the purposes of this paper, it was shortened to fit half a page. All names appearing in this and the next subsection were changed to protect privacy. Fig. 1 presents Bethy in her living room. The photograph is an example of the photograps the study participants were asked to take that present their daily life and the objects and incidents at home. The newspaper on the table contains television program listings. Bethy said: "Yes, there are enough interesting programs on TV. ..For me, it's more important to read the books. I always have something to do if there is nothing on TV that interests me."

Five study participants' innovations of future interactive television programs and applications are presented in Table 1. 75 innovations altogether were made by ten study participants. As is seen in Table 1, the user preferences and innovations of 
Table 1. User preferences for future interactive television programs and applications

\begin{tabular}{|c|c|}
\hline $\begin{array}{l}\text { Name, Age (years), } \\
\text { Profession }\end{array}$ & Users' concepts \\
\hline $\begin{array}{l}\text { 1. Henri, 16, High } \\
\text { school student }\end{array}$ & $\begin{array}{ll}\text { - } & \text { Internet chat on TV via set-top-box or a mobile phone } \\
\text { - } & \text { Email and SMS on TV while watching the TV } \\
\text { - } & \text { Load books and magazines on TV } \\
\text { - } & \text { TV games } \\
\text { - } & \text { Interactive role playing game, new episode every week } \\
\text { - } & \text { TV reminds him of important events } \\
\text { - } & \text { Demonstration and information sharing of his hobby (judo) } \\
\text { - } & \text { Information on travel destinations and cities } \\
\text { - } & \text { Holiday reservation requests on TV }\end{array}$ \\
\hline $\begin{array}{l}\text { 2. Patrick, 27, Product } \\
\text { manager }\end{array}$ & 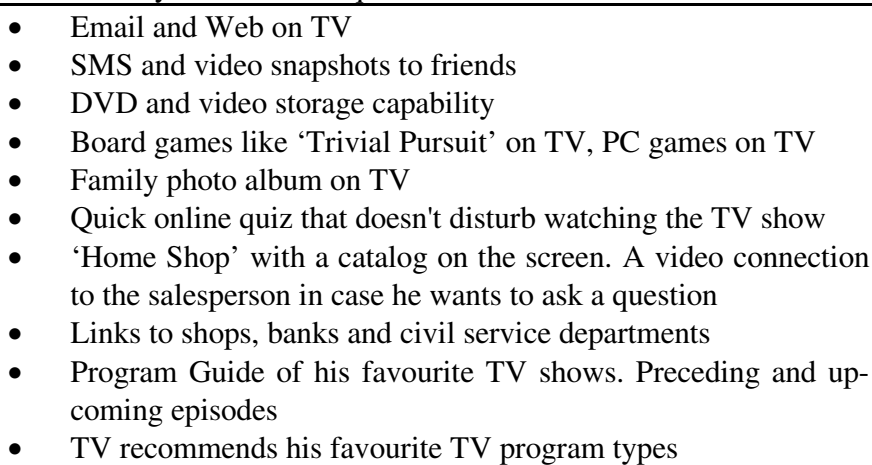 \\
\hline $\begin{array}{ll}3 . \quad \text { Alicia, } & 34, \\
\text { Children's nurse } & \end{array}$ & 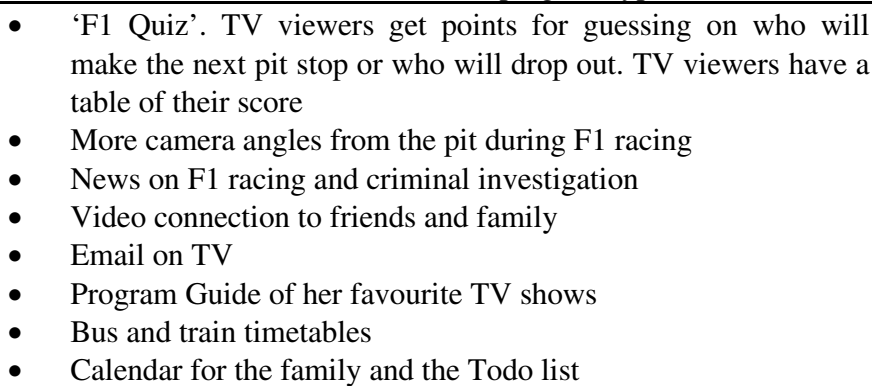 \\
\hline $\begin{array}{l}\text { 4. Bruce, 46, Chief } \\
\text { coastguard }\end{array}$ & 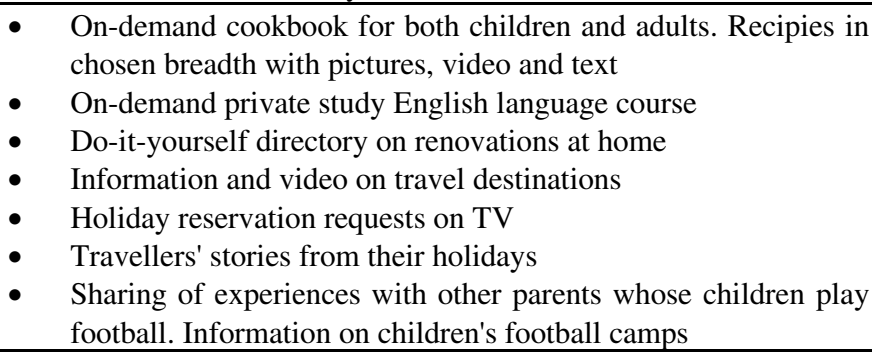 \\
\hline 5. Bethy, 78, Retired & $\begin{array}{l}\text { - Interactive 'Wheel Of Fortune' program } \\
\text { - } \quad \text { All-day TV channel for retired people that presents Church } \\
\text { services, programs on current affairs, gymnastic exercises and } \\
\text { stories on recovery from diseases }\end{array}$ \\
\hline
\end{tabular}


future services are quite personal. If we try to find some common concept for these five TV viewers it must be Email on TV. Other favourite concepts were SMS on TV, TV games, video connection on TV, Electronic Program Guides (EPGs), information on travel destinations and Quiz on the ongoing TV show.

\subsection{Design Sessions}

There were five design sessions in the public service broadcasting company YLE. A set of user profiles was selected, namely those presented in Table 1. The aim of each session was to concentrate specifically on one TV viewer at a time instead of groups of people familiar from the audience research. The session participants designed new concepts of interactive television programs for this particular TV viewer. As a feedback, they were given the TV viewer's own innovations at the end of the session. Altogether 29 new concepts were designed. Table 2 represents designers' views on which interactive concepts would suit these users. Most of the new concepts really are new and do not yet exist on Finnish television. Some concepts like hosted TV chats, 'Entertainment Program For Teenagers' and 'Local Events' programs already have some examples to draw influence from.

\subsection{Analysis of Results}

The user study resulted in 75 innovations altogether which were made by ten user study participants. In this paper, innovations made by five TV viewers were presented. The innovations were based on personal preferences. The most popular concept was Email on TV. Other favourite concepts were SMS on TV, TV games, video connection on TV, Electronic Program Guides (EPGs), information on travel destinations and Quiz on the ongoing TV show. TV viewers' concepts can be considered as new or novel and they do not yet exist on Finnish television except for some interactive SMS based TV games and an EPG in the set-top-box. It is likely that in the future we well see many SMS based TV games and Quizzes on the ongoing TV show, as the mobile phone density is very high in Finland and people use them with pleasure.

The five design sessions in the broadcasting company resulted in altogether 29 interactive concepts. The concepts differ significantly from each other from session to session and no common concepts were found. There are however two types of user interaction that were in designers' favour. First, designers innovated concepts of TV shows that rely on the TV viewer to send his or her opinion or story to the show. For example 'Criminal Investigation' program for Alicia, 'Our Family Life' for Bruce and 'Recent History' for Bethy are concepts that rely on the TV viewer to send solutions, stories and recollections to the show. The other type of interaction asks for TV viewers' participation already during the show. For example 'Science Program For Teenagers' for Henri, 'Chat For Formula 1 Fanatics' for Alicia, 'Wheel Of Fortune' for Alicia and Bethy and 'Sing Along' for Bethy are based on user interaction during the show, not before or after the show. 
Table 2. Designers' views on what would suit the user

\begin{tabular}{|c|c|}
\hline Session & Designers' views \\
\hline 1. Henri & $\begin{array}{l}\text { - 'Science Program For Teenagers'. Themes of the program vary from the new } \\
\text { technology to how Darude makes computer music. People of different ages and } \\
\text { backgrounds do the program. Henri can send his opinion on the 'Question Of } \\
\text { The Week' to the show with an SMS } \\
\text { 'Entertainment Program For Teenagers'. Young celebrities like singers and } \\
\text { musicians appear in the program. There are funny mishaps during the show, } \\
\text { nothing too profound. User interaction with an SMS }\end{array}$ \\
\hline 2. Patrick & $\begin{array}{l}\text { - 'Personalized News'. A program of rapid pace covering only prespecified } \\
\text { - } \quad \text { TV gamects Patrick has chosen for himself } \\
\text { - Interactive features on movies. Patrick sees background information on his } \\
\text { favourite movie, for example interviews with the actors, the special effects and } \\
\text { the shooting of the movie } \\
\text { 'Interactive Action' series. Patrick answers questions or solves small problems } \\
\text { and collects points } \\
\text { 'Interactive Nature' series. Patrick sees background information on the crea- } \\
\text { tures. He can also take snapshots of both domestic and wild animals and send } \\
\text { them to the show }\end{array}$ \\
\hline 3. A & $\begin{array}{l}\text { - 'Chat For Formula } 1 \text { Fanatics' program. Alicia can chat with other Formula } 1 \\
\text { experts about the race. It is a hosted chat in Finnish for her convenience and } \\
\text { she can watch the race at the same time in the background } \\
\text { 'Criminal Investigation' program. Based on both historical material and } \\
\text { dramatized scenes. First some clue is given to the case and then the TV viewers } \\
\text { are asked to send their solution to the mystery, an art robbery, etc. The show } \\
\text { can also include cases from her neighbourhood } \\
\text { 'Wheel Of Fortune' program. Alicia can write her guess while watching the } \\
\text { program and win instantly. The winner gets her name on TV } \\
\text { 'Who Wants To Be A Millionaire' for fast answers from the TV viewers }\end{array}$ \\
\hline 4. Bruce & $\begin{array}{l}\text { - 'Our Family Life'. The program tells about what it is like to live in a one- } \\
\text { family house as a type of living. Themes vary from the maintenance of the } \\
\text { house to kitchen work, gardening and parenting. There are also examples of } \\
\text { 'How To Get Along With Your Neighbour'. Bruce can make a call and dictate } \\
\text { his own story on the } 24 \text {-hour phone line. The next week he sees his story } \\
\text { dramatized on TV. All TV viewers can now call the show and give their sug- } \\
\text { gestions as how to best solve the situation }\end{array}$ \\
\hline 5. B & $\begin{array}{l}\text { - 'How To Utilize The New Technology' program. Short and humoristic in style, } \\
\text { - 'Local Events' program. Bethy sees what's happening in her home town } \\
\text { - 'Wheel Of Fortune' for Bethy to type in her guesses. Very quiet in pace } \\
\text { - 'Recent History' program addressing issues from politics to pop music, to } \\
\text { fashion and daily life. The program proceeds one year at a time. Bethy can } \\
\text { send her interesting recollection to the show. The program is a way to transfer } \\
\text { the cultural heritage, to maintain the memory of a generation } \\
\text { 'Sing Along' program. TV viewers choose by voting both the next artist and } \\
\text { the song this artist will perform. Bethy can sing along with the show } \\
\text { 'Cuisine Program For Home Chefs'. Traditional Finnish food made easy. Bethy } \\
\text { can send recipes from her childhood to the show }\end{array}$ \\
\hline
\end{tabular}


Most of designers' concepts are new and do not yet exist on Finnish television. Some concepts like the hosted TV chat for Alicia, 'Entertainment Program For Teenagers' for Henri and 'Local Events' program for Bethy do have some examples to draw influence from. Of the new concepts of two types of user interaction, it is most likely that the concepts of instant user interaction will succeed. Watching the television is considered a pleasant leisure time activity that does not involve too much concentrated brainwork. Interaction before or after the show would need quite a lot of user motivation.

When we compare the user preferences to designers' views on what would suit the particular TV viewer, we see that designers' concepts suit Henri and Patrick quite well. For Alicia, who is a home centered, the designers could have created a program on family issues. For Bruce, who is both information and entertainment oriented, the designers could have created a program on travelling. He was also interested in ondemand applications about cooking, English language studies and home renovation. As on-demand applications were not considered TV programs, designers didn't create any of these. For Bethy, the designers could have created programs on Church services or health and fitness programs for retired people. As many of these preferences are quite personal, it is not easy to say if the new concepts will appeal to a broad range of TV viewers.

\subsection{Analysis of Methods}

The five design sessions in the broadcasting company were started with reading a given user profile. It was found during the sessions that sometimes the session participants considered the TV viewer as older or younger than the group of people they considered 'their audience'. It could increase the session participants' motivation and commitment to the design session if they could choose their favourite user profile beforehand. Also, the reading of the profile shouldn't take more than 10 minutes as the idea is to use the material to provoke lively discussions and not to 'study' the material in great detail.

The other design methods used were storytelling and role playing. When the two session participants found an interesting user comment, they started to imitate fictitious program hosts, television announcers or members from the studio audience. This was a fast method to visualize their new ideas. The session participants considered the results from an interview with the TV viewer and the user's innovations especially useful as these contained data of user's tastes and preferences and stories of his daily life. This material was quite easy to exploit in storytelling and role playing during the design session.

As the user study method is a time-consuming exercise including data collecting and data analysis, it is recommended to start early. The user profiles are then reusable for any future design sessions. 


\section{Conclusion}

This paper presented results from a user study and a set of design sessions conducted in a broadcasting company. The user study put emphasis on finding user preferences and expectations instead of particular user needs. The design sessions concentrated specifically on one TV viewer at a time. The use of individual user profiles was a new idea in this broadcasting company as today they use the results from the audience research as a basis for their design work. Innovations of future interactive applications were created by both TV viewers and designers. Future research has two goals arising from the needs of product development. First, we want to know which concepts are likely to suit a large audience and second, we want to make scenarios of selected new concepts to get feedback from TV viewers.

\section{References}

1. Blomberg, J., Giacomi, J., Mosher, A., Swenton-Wall, P.: Ethnographic Field Methods and Their Relation to Design. In: Schuler, D., Namioka, A. (eds.): Participatory Design: Principles and Practices. Lawrence Erlbaum Associates, Hillsdale, NJ, USA (1993) 123 155

2. Buchenau, M., Suri, J. F.: Experience Prototyping. In: Conference proceedings on Designing interactive systems DIS '00: processes, practices, methods, and techniques. ACM Press, New York, NY, USA (2000) 424-433

3. Erickson, T.: Notes on Design Practice: Stories and Prototypes as Catalysts for Communication. In: Carroll, J. M. (ed.): Scenario-Based Design: Envisioning Work and Technology in System Development. Wiley, New York, NY (1995) 37-58

4. Eronen, L.: Combining Quantitative and Qualitative Data in User Research on Digital Television. In: Proceedings of the 1st Panhellenic Conference with International Participation on Human-Computer Interaction PC HCI 2001. Typorama Publications, Patras, Greece (2001) 51-56

5. Eronen, L.: Design of Future Television. In: Proceedings of the HF2002 Human Factors Conference, a joint Conference of the Ergonomics Society of Australia (ESA) and the Australian CHISIG. Melbourne, Australia (November 2002) 8 pages

6. Eronen, L., Vuorimaa, P.: User Interfaces for Digital Television: a Navigator Case Study. In: Proceedings of the Working Conference on Advanced Visual Interfaces AVI 2000. ACM Press, New York, NY, USA (2000) 276-279

7. Gaver, B., Dunne, T., Pacenti, E.: Design: Cultural Probes. Interactions, Vol. 6, No. 1. (1999) 21-29

8. Logan, R. J.: Behavioral and Emotional Usability: Thomson Consumer Electronics. In: Wiklund, M. E. (ed.): Usability in Practice: How Companies Develop User-Friendly Products. AP Professional, Boston, MA, USA (1994) 59-82

9. Merialdo, B., Lee, K. T., Luparello, D., Roudaire, J.: Automatic Construction of Personalized TV News Programs. In: Conference proceedings of the seventh ACM international conference on Multimedia. ACM Press, New York, NY, USA (1999) 323-331

10. O'Brien, J., Rodden, T., Rouncefield, M. and Hughes, J.: At Home with the Technology: An Ethnographic Study of a Set-Top-Box Trial. ACM Transactions on Computer-Human Interaction 6, 3 (September 1999), 282-308

11. Rubin, H. J., Rubin, I. S.: Qualitative Interviewing: The Art of Hearing Data. Sage Publications, Inc., Thousand Oaks, CA, USA (1995) 